\title{
A LITERATURA COMO GESTO DE RESISTÊNCIA EM “O SAGRADO PÃO DOS FILHOS”, DE CONCEIÇÃO EVARISTO
}

\section{LITERATURE AS AN ACT OF RESISTANCE IN “O SAGRADO PÃO DOS FILHOS”, BY CONCEIÇÃO EVARISTO}

\author{
Maria Valdenia da SILVA ${ }^{1}$ \\ Jaquelânia Aristides PEREIRA ${ }^{2}$ \\ Maria de Fátima Vasconcelos da $\operatorname{COSTA}^{3}$
}

\begin{abstract}
Resumo: Conceição Evaristo é uma escritora afro-brasileira de grande relevância no cenário nacional atual, sobretudo por construir uma literatura de resistência voltada para as questões etnorraciais e de gênero, num movimento interseccional que envolve também a categoria de classe. Sua produção literária, no geral, é pautada na sua vivência de mulher negra submetida às condições de subalternização diversas no Brasil e pela evocação da memória de seus ancestrais africanos como forma de construir um contradiscurso sobre a luta dos negros no nosso país. Neste artigo, apresentamos o nosso discurso de compreensão do conto "O sagrado pão dos filhos", do livro Histórias de leves enganos e parecenças, resultante de nossa leitura e interpretação desse texto e da experiência de leitura compartilhada num círculo de leitura com participantes do evento Memórias de Baobá, em Fortaleza. Utilizamos como fundamento da análise literária do conto os dispositivos da crítica literária, da abordagem bakhtiniana da linguagem e da análise do discurso francesa. Podemos dizer que o conto "O sagrado pão dos filhos" foi percebido em sua tessitura estética complexa e reveladora de como a literatura constrói o humano, configurando um gesto decolonial, que faz ecoar vozes silenciadas subjacentes ao processo de subalternização racial tanto econômico quanto simbólico.
\end{abstract}

Palavras-chave: Literatura afro-brasileira. Conto. Crítica. Resistência. Círculos de leitura.

\begin{abstract}
Conceição Evaristo is an Afro-Brazilian writer of great relevance in the current Brazilian scenario. She has contributed for building a resistance literature focused on ethno-racial and gender issues, in an intersectional movement which also includes the class category. Her literary production, in general, is guided by her experience as a black woman, submitted to various subaltern conditions in Brazil and by evoking the memory of her African ancestors as a way of constructing a counter-discourse about the black struggle in the country. This paper presents a comprehension discourse of the short story "O sagrado pão dos filhos", from the book Histórias de leves enganos e parecenças, which resulted from our reading and interpretation of this text and from the experience of a shared reading in a reading circle at Memórias de Baobá, an even held in the city of Fortaleza, Brazil. Literary criticism, Bakhtinian approach of language as well as French discourse analysis were used as basis for the literary analysis of the short story. "O sagrado pão dos filhos" was perceived in its complex aesthetic texture revealing how literature builds the human, setting up a decolonial gesture, echoing silent voices that are subjacent to the racial process of economic and symbolic subalternization.
\end{abstract}

Keywords: Afro-Brazilian literature. Short story. Critical. Resistance. Reading circles.

\footnotetext{
${ }^{1}$ Doutora em Letras pela Universidade Federal da Paraíba. Professora adjunta do Curso de Letras e do Mestrado Interdisciplinar em História e Letras da Faculdade de Educação, Ciências e Letras do Sertão Central, vinculada à Universidade Estadual do Ceará. E-mail: maria.valdenia@uece.br.

${ }^{2}$ Doutora em Letras pela Universidade Federal da Paraíba. Professora adjunta do Curso de Letras e do Mestrado Interdisciplinar em História e Letras da Faculdade de Educação, Ciências e Letras do Sertão Central, e do Mestrado Profissional em Letras, vinculados à Universidade Estadual do Ceará. E-mail: jaquelania.pereira@uece.br.

${ }^{3}$ Doutora em Educação Brasileira pela Universidade Federal do Ceará, Pós-doutora em Psicologia pela Universidade Federal de Pernambuco. Professora titular do Programa de Pós-graduação em Educação Brasileira da Universidade Federal do Ceará. E-mail: dphatyma @gmail.com.
} 


\section{Considerações iniciais}

A crítica literária brasileira considera Conceição Evaristo uma das vozes mais representativas da literatura afro-brasileira, em especial por sua múltipla atuação como ensaísta, contista, poeta, professora e militante dos movimentos sociais negros, entre os quais se destaca o grupo Quilombhoje, responsável pela publicação dos Cadernos Negros, que tem se configurado como um espaço de visibilidade para a literatura afro-brasileira contemporânea. Em um de seus ensaios, a escritora mineira afirma existir no Brasil um corpus representativo da produção literária de escritores negros, marcado "por uma subjetividade construída, experimentada, vivenciada a partir da condição de homens negros e de mulheres negras na sociedade brasileira." (EVARISTO, 2009, p. 17).

Tratando-se do texto evaristeano, essa subjetividade resulta em uma escrita inteiramente pautada na condição de mulher negra, evidenciada nos enredos, nas histórias de vida das personagens e nos temas abordados. Em seu livro Histórias de leves enganos e parecenças (2016a), Conceição Evaristo retoma temas que dialogam com seus textos anteriores, seja pela evocação da memória de seus ancestrais africanos escravizados no Brasil, seja pelas marcas de resistência construídas nas trajetórias de suas personagens, em sua maioria, mulheres vítimas da pobreza, do racismo e da violência de gênero, consubstanciando o que se pode denominar de realismo social.

O conto "O sagrado pão dos filhos", do livro Histórias de leves enganos e parecenças, possui uma tessitura estética complexa e reveladora de como a literatura constrói o humano, elaborando sentidos, lançando luz sobre fatos, contrapondo posicionamentos, acionando a sensibilidade do leitor, incitando-o a pensar/agir, pelo trabalho de criação textual dos enunciados. Por essas qualidades, exige também do leitor deslocamentos de posições para que possa ouvir a pluralidade de vozes que tencionam os sentidos do texto.

Pretende-se, neste artigo, empreender um percurso analítico que se presta a demonstrar de que modo a criação literária sensibiliza e convoca o leitor para tomar lugar na cena enunciativa. Para tanto, abordaremos o texto a partir do dispositivo da crítica literária, da abordagem bakhtiniana da linguagem, que concebe o dizer como um acontecimento que se realiza em condições situadas historicamente, no quadro de relações de poder entre os interlocutores, e da análise do discurso francesa. Dada a natureza constitutivamente dialógica dessa atividade, ou seja, dirigida a uma alteridade, os sentidos nunca podem ser estabilizados, uma vez que os efeitos de sentido são resultantes dessa interação (BAKHTIN/VOLOCHÍNOV, 1996). A natureza aberta à inscrição do outro das práticas linguageiras situa o dizer num 
horizonte social de valor, o que implica uma responsabilidade ética. Portanto, a participação dinâmica do leitor responde, em alguma medida, pelo embate de vozes "audíveis" no texto. O gesto literário visa mobilizar o leitor para tomar parte da cena de enunciação construída pelo texto.

No caso da categoria da resistência, tomaremos como base os estudos de Bosi (1996; 2002), numa evidenciação do texto da literatura feminista negra como um gesto decolonial. Sob esse aspecto, tal gesto faz ecoar vozes silenciadas, trazendo à superfície textual o conflito subjacente ao processo de subalternização racial tanto econômico quanto simbólico.

Este artigo apresenta o resultado de uma interpretação coletiva do conto "O sagrado pão dos filhos", somando a nossa leitura e interpretação, elaboradas a partir de nossa interação demorada com o texto evaristeano, enquanto leitoras e pesquisadoras do texto literário, à leitura compartilhada com alunos numa experiência de círculo de leitura, no evento IX Memórias de Baobá: 15 Anos de Lei 10.639: Pertencimento, Espiritualidade e Educação, ocorrido em Fortaleza em 2018. Nesse evento, trabalhamos alguns contos e poemas de Conceição Evaristo, a partir da metodologia do círculo de leitura proposto por Cosson (2014). Neste artigo, nos concentraremos apenas na experiência com o conto acima referido.

\section{Aspectos estruturais do conto "O sagrado pão dos filhos" e sua análise discursiva}

Em termos estruturais, o conto "O sagrado pão dos filhos" se organiza em duas partes: a primeira é uma espécie de prólogo em que a narradora, em primeira pessoa, apresenta a gênese da história que vai contar, destacando a influência ancestral, numa clara referência à constatação de Benjamin (1986), para quem o ato de narrar consiste na prática da repetição. A segunda parte, narrada em terceira pessoa, traz o relato propriamente dito da narrativa.

$\mathrm{O}$ início do conto também orienta o leitor para o contexto em que a narrativa se desenrola, chamando a atenção para o espaço da sociedade brasileira, notadamente no que diz respeito ao processo de sua formação, considerando os modos de exploração aos quais foi submetido o povo negro, inclusive, o apagamento de suas raízes culturais e as formas estereotipadas de sua representação, demarcadas pelo olhar do colonizador. Ao criticar as representações de seu povo na literatura canônica, Conceição Evaristo questiona: "Estaria a literatura, assim como a história, produzindo um apagamento ou destacando determinados aspectos em detrimento de outros, e assim ocultando os sentidos de uma matriz africana na sociedade brasileira?" (EVARISTO, 2016b, p. 105) 
Tratando-se de um gênero curto, o conto dá a conhecer os aspectos gerais da história de vida da família Pedragal e da empregada doméstica Andina Magnólia, centrando seu foco nessa personagem, ora inserida no ambiente do trabalho, ora situada em casa com os seus filhos na ceia de multiplicação dos farelos do pão.

No que concerne à análise do discurso do texto, na esteira das ideias de Maingueneau (2008), sua cena englobante diz respeito ao discurso literário como a forma de interpelação do leitor e, nesta, o gênero conto a definir o lugar e o tempo da situação de enunciação. A cena de enunciação do texto, conjugação da cena englobante e da genérica, é contextualizada no limiar dos anos 1940, refletindo a sociedade brasileira marcadamente influenciada pela mentalidade colonial, pensamento que perdura até os dias de hoje. O eixo narrativo é de um acontecimento desse passado, onde duas mulheres se defrontam. Elas estão em posição social desigual. A primeira, uma mulher negra e mãe, está no papel subalterno em relação à outra, uma mulher branca e igualmente mãe, que goza de confortável condição econômica em relação à primeira. O texto faz saber que a relação de subalternização de uma é histórica e, pela forma como se dá essa relação, há uma imobilidade intergeracional entre as linhagens das duas personagens. Dessas particularidades, a autora, com habilidade, dá a conhecer os antecedentes de uma delas, ironicamente identificada como Isabel Pedragal, como descendente de cruéis exploradores de escravos. O nome Isabel possivelmente se dá em referência à princesa que assinou a lei áurea, que libertou os escravos no Brasil. No entanto, sabemos que essa libertação é questionável na medida em que não se criaram condições mínimas de autonomia, sobretudo financeira, para os negros e negras, os quais permaneceram subordinados aos senhores brancos, realizando trabalhos escravos em troca de migalhas de comida e de abrigo.

Como se não bastasse referenciar um nome ligado à monarquia no conto, um dos sobrenomes da personagem branca e de posses é Pedragal, a sugerir uma estabilidade pétrea na sua linhagem e uma dureza em suas atitudes na relação com a alteridade da empregada. O outro sobrenome, Correa, sugere tanto a chibata que açoitava os escravos como o aprisionamento a que eram submetidos. Do outro lado, a escrava, cujo nome é Andina Magnólia dos Santos, descende de uma linhagem de pessoas que, por longo tempo, tem servido à família Pedragal, vivendo em condições de subordinação econômica e cultural. Curiosamente, Magnólia ${ }^{4}$ é nome de uma árvore ornamental que abundantemente produz grandes flores perfumadas, de forma

\footnotetext{
${ }^{4}$ [Botânica] Árvore (Magnolia grandiflora) da família das magnoliáceas, nativa dos Estados Unidos da América, de flores grandes e brancas, cultivada como ornamental. Conferir: https://dicionario.priberam.org/Magnolia.
} 
cônica e de cor branca, amarela ou rosa. É no contraponto entre a opulência financeira, soberba e mediocridade de Isabel Correa Pedragal e a miséria financeira, riqueza de caráter e dignidade de Andina que a autora posiciona as personagens. Nota-se que os seus nomes são motivados, estando em consonância com suas características psicológicas: enquanto Isabel Correa Pedragal se mostra como uma personagem de coração de pedra, que não tem sororidade com a outra mulher com a qual conviveu desde a infância e que lhe é subordinada, negando-lhe um pedaço de pão para os filhos, Andina recebe os atributos de uma flor nobre, a Magnólia, bela, resistente e perfumada. Além disso, o nome Andina também aponta para o caráter de resistência da personagem, que está sempre em movimento, resistindo como pode às opressões de classe e de raça. Ao mesmo tempo, Andina pode evocar a grandiosidade de sua pessoa e de seus gestos, na medida em que o nome possui referência direta à América Andina, conjunto de países da América do Sul de grande extensão territorial (em torno de 5,4 milhões de quilômetros quadrados), cruzados pela Cordilheira dos Andes: Bolívia, Peru, Equador, Colômbia, Chile e Venezuela. Essa magnitude de caráter de Andina é reforçada pelo sobrenome Santos, referência religiosa que aponta para a bondade da personagem.

Apesar das diferenças sociais das personagens femininas, elas são igualmente mães, e Magnólia possui uma expertise: sabe fazer um pão, tido como "a delícia das delícias", que aprendeu com sua mãe e que é saboreado por todos da casa-grande. Já os filhos de Magnólia, ainda não haviam saboreado tal delícia, dada a dificuldade da mãe de obter os ingredientes. Ao pedir à patroa um dos pães para levar para os filhos, esta não só se recusa a atender ao pedido, como passa a servi-la, exigindo que Magnólia passasse a comer a fatia do pão diante dela para garantir que não levasse nada para casa. Nesse ponto, tem início a urdidura da resistência, na medida em que Andina Magnólia, ao comer o pão, deixa cair os farelitos nos entresseios, a partir dos quais se dará a multiplicação do alimento.

$\mathrm{Na}$ história das mulheres negras afrodescendentes, o próprio ofício de contar e/ou escrever histórias constitui uma forma de resistência no embate diário contra o sistema de opressão escravagista vivido historicamente no Brasil, como destaca a escritora Conceição Evaristo:

as mulheres das classes subalternas já tinham atitudes e estratégias de enfrentamento diante da dureza do cotidiano. Histórias, ficções criadas por elas funcionavam como discursos de resistência e mais do que isso, como suporte, amparo emocional diante do sofrimento. Formas ficcionais que buscam resistência podem ficcionalizar o cotidiano, sobrepujando a dor. Para além das impossibilidades de alimentar os filhos, cria-se uma ficção que os filhos eram alimentados com as águas das mãos da mulher que guardavam restos de farinhas do pão que ela preparava na casa-grande. (EVARISTO, 2016b, p.7). 
Sabemos que o processo de escravidão dos negros africanos não foi aceito por eles passivamente. Historiadores relatam formas diversas, individuais ou coletivas, de resistência, sendo as mais comuns: rebeliões, ainda em solo africano quando aprisionados à espera da viagem para o Brasil; fugas das fazendas para os quilombos; ataques aos feitores, senhores e às plantações; preservação das manifestações artísticas (cantos, danças); religiosas (culto às divindades de origem, especialmente manifestado através do sincretismo) e através da culinária africana, que se presentificava tanto nas senzalas, quanto nas cozinhas das casas-grandes, como narrado no conto "O sagrado pão dos filhos". Neste, Andina Magnólia, aparentemente, obedece à patroa, mas não sem deixar cair uns "farelitos no peito por debaixo da blusa. E todos os dias, a mãe levava o pão sagrado para os filhos. O alimento ainda vinha acompanhado de leite" (EVARISTO, 2016a, p. 39), embora a mãe já tivesse desmamado a mais nova das filhas há bastante tempo. Com a multiplicação das migalhas, a autora constrói uma cena enunciativa em que contrapõe o binômio opulência econômica/mesquinhez de uma das personagens à miséria econômica/generosidade da outra. Para isso, sem alterar magicamente a situação, como a licença ficcional permitiria, lança mão de marcadores textuais, o uso de diminutivos (farelitos, sinhazinha, pedragalzinhas etc), ora em tom pejorativo ao se referir à sinhá e suas filhas, e de valor afetivo, delicado, ao tratar da serviçal.

Toda a narrativa procura recuperar a humanidade de Magnólia, invisibilizada e violentada pela prepotência dos senhores e sinhás escravocratas. Isso se materializa na crítica de Duarte sobre a obra de Conceição Evaristo, quando afirma que:

Seus contos aliam a denúncia social a um lirismo trágico, que remete ao mundo íntimo
dos humilhados e ofendidos, tomados como seres sensíveis, marcados não apenas
pelos traumas da vida lúmpem [sic], mas também por desejos, sonhos, lembranças.
(DUARTE, LOPES, on-line).

Na cena enunciativa do texto, é narrada uma memória de infância, fazendo menção à linhagem feminina ancestral da narradora. Com isso, ela credencia a sua narrativa com a voz dos seus antepassados, que é o que pretende legitimar. Os poderosos, de certo modo, perdem o lugar de protagonistas, sendo descritos pelo enunciador como anti-heróis. Enumera-se um conjunto de bens que vem se acumulando desde a colonização e que vai desde "terras e mais terras, usinas, gados, armazéns, farmácias, fábricas de tratores, de cervejas, de perfumes, e não sei mais de quê"' (EVARISTO, 2016a, p. 37), à custa da pauperização dos que trabalham. Estes últimos, entretanto, são apresentados exatamente como dotados das mesmas características humanas (são crianças, têm religião, casam-se, têm filhos), exceto no que se refere ao trabalho, que só aparece na ação dos personagens subalternizados. 
Os usos das conjunções concessivas e adversativas, curiosamente, funcionam como um dispositivo de resistência à degradação imposta pelo regime de exploração e da sua denúncia. Ao descrever a situação da personagem negra, esta é posicionada como aquela que é submetida a condições adversas, sendo descrita como "saco-de-pancadas" e pequena babá escravizada que resiste como pode à exploração e à violência: "Andina Magnólia cresceu forte, bonita e trabalhadora, apesar de tudo. Do mesmo modo [...] Apesar, do trabalho do marido, muitas vezes faltava alimento [...] aparentemente obedecia, mas à medida que comia, deixava alguns pedaços, farelitos cair no peito" (EVARISTO, 2016a, p. 38/39. Grifos nossos). "Por fim, Andina Magnólia dos Santos, filha de Jacinta dos Santos e de Bernardino Pereira, cresceu sob os mandos da casa-grande, embora tenha nascido em 1911 (após a abolição)" (EVARISTO, 2016a, p. 38. Grifo nosso).

A narradora/enunciadora apresenta a construção da desigualdade estrutural de classe, interpelando o leitor, coenunciador do discurso, a tomar posição:

Assim a vida seguia. Andina cresceu e as Pedragalzinhas também. Casaram-se todas.
Andina com um jovem trabalhador do campo, cujas origens provinham também de
africanos escravizados em terras brasileiras. As moças da casa-grande misturaram
suas fortunas com as dos primos ricos ou com filhos dos velhos amigos da família,
também soberbos e afortunados. Andina foi destinada a trabalhar com uma das novas
senhoras do Império Pedragal. Isabel Correa Pedragal, antes a menina Bebel da casa-
grande, a quem Andina havia servido como babá, apesar, da mesma idade.
(EVARISTO, 2016a, p. 38. Grifo nosso).

Nota-se que, no recorte do texto a seguir, há uma polêmica de vozes que estabelece uma relação interdiscursiva com o discurso religioso, também representativa do trabalho de resistência. Tal qual a aparente obediência de Magnólia, seus pais cultivavam o deus Zâmbi, sem recusar abertamente o cristianismo:

Temendo a "pretinha da casa", - assim era chamada pela Senhora Correa e pelos familiares - se enveredasse pelos caminhos não católicos, a exemplo de seus pais que rezavam para Jesus Cristo e um tal de Zâmbi, Dona Correa esmerou-se em plantar na menina a fé nas coisas da igreja de Padre Joaquim. E assim, Andina Magnólia foi batizada e encaminhada para o catecismo. (EVARISTO, 2016a, p. 38).

Como no início, em que a autora faz referência a sua linhagem matriarcal e ao pão sagrado, o conto é encerrado com uma celebração, na qual é invocado o Deus Zâmbi (referência à religiosidade africana), a quem é atribuído o poder de transformar o mínimo trazido por Magnólia na fartura do alimento para os seus protegidos. Ao trazer para a cena da enunciação a voz dos deuses, operando o milagre da multiplicação do pão, a autora faz um gesto de afirmação da cultura oprimida pelas forças da opressão através de uma relação interdiscursiva de natureza crítica. Vale destacar que, apesar de ser invocada a figura de um deus masculino 
para o milagre da multiplicação dos farelos, isso só ocorre por intermédio da matriarca que providenciou o depósito dos farelos nos seios, fonte de fertilidade. Esse princípio sagrado encontra semelhança com o milagre do vinho nas bodas de Canaã da Galileia, narrada no livro de João (2:1-11), em que Maria providencia a água para Jesus transformar em vinho e servir aos convidados. Ambas as personagens femininas cooperam para o evento do milagre. Esse cruzamento religioso aponta também para o próprio sincretismo religioso da personagem e para a formação religiosa do brasileiro, bem como para as semelhanças de caráter das figuras sagradas em religiões diversas e das figuras míticas.

Praticamente em todas as narrativas de Histórias de leves enganos e parecenças, o insólito que, segundo a prefaciadora Assunção Sousa, pode ser denominado de realismo animista, na acepção do escritor angolano Pepetela se instaura:

\footnotetext{
Isto porque a existência da atuação de forças da natureza, da alteração dos fenômenos que modificam a ordem natural das coisas, a crença em entidades capazes de intervir na rotina dos personagens, etc. são estratégias concebidas por um modus operandi revelador da maneira de pensar, de ser e de existir de uma dada comunidade cujas origens advêm da diáspora africana. (SOUSA, In: EVARISTO, 2016a, p. 7).
}

Essa diáspora africana trouxe em seu bojo todo um cabedal de saberes da cultura ancestral que o processo de colonização não conseguiu apagar, cultura que pulsa na escrevivência de Conceição Evaristo e nos faz beber dessa fonte como necessidade cotidiana, preenchendo, de certa forma, a lacuna que ficou na nossa formação cultural no tocante às nossas origens como povo negro.

\section{Literatura de resistência: conjugação do prazer e da fruição}

\subsection{O conto "O sagrado pão dos filhos" pelo filtro da teoria barthesiana.}

De acordo com Barthes, há dois tipos de textos: o texto de prazer: "aquele que contenta, enche, dá euforia; aquele que vem da cultura, não rompe com ela, está ligado a uma prática confortável da leitura", e o "texto de fruição: aquele que põe em estado de perda, aquele que desconforta (talvez até um certo enfado), faz vacilar as bases históricas, culturais, psicológicas do leitor, a consistência de seus gostos, de seus valores e de suas lembranças, faz entrar em crise sua relação com a linguagem". (BARTHES, 2008, p. 20-21).

O conto de Conceição Evaristo conjuga essas duas instâncias do texto elencadas por Barthes, pois usa uma linguagem próxima da oralidade dos antigos narradores, podendo suscitar no leitor um estado de conforto, um sentir-se em casa, sendo um texto de prazer, ao mesmo tempo em que expõe no conto as feridas do mito da democracia racial brasileira, numa 
desaprovação da violência sofrida pela mulher negra em sua relação de trabalho com a mulher branca e rica, através de uma linguagem que se utiliza, algumas vezes, de certas construções que não se entregam facilmente à compreensão do leitor, exigindo-lhe uma postura de pesquisador. Esse aspecto do texto de fruição, no conto "O sagrado pão dos filhos", pode inquietar o leitor, sobretudo diante das atitudes desumanas da patroa para com a empregada negra e sua família, sem falar em toda a vida subalterna da personagem negra servindo à família Pedragal. A esse respeito, a escritora afirma: “[...] As realidades são difíceis e desagradáveis sim, mas é este material que eu escolhi como conteúdo literário. Ao mesmo tempo em que são difíceis e desagradáveis, eu acho que escrever é uma forma de resistir e vencer." (EVARISTO, 2016b, p. 94). Nesse sentido, o tex to literário assume sua função social:

Nossa história de resistência é muito pouco contada: até os anos 1980, a ciência histórica valorizava a canetada da Princesa Isabel e não a história dos quilombos. E por isso também a academia tem dificuldade de lidar com nossos textos de memória: assim como nega nosso passado de protagonismo, nega nosso direito à memória. Acho que a literatura é um espaço em que a gente pode reivindicar ou afirmar nosso direito à memória. (EVARISTO, In: LIMA, 2017, on-line).

É essa resistência que formata a sua escrevivência e a de outras escritoras negras, processo que é atravessado e costurado com suas vivências, com sua condição de mulher negra na sociedade brasileira.

A este respeito, Alfredo Bosi, em seus estudos acerca da literatura de resistência, assinala:

A escrita resistente não resgata apenas o que foi dito uma só vez no passado distante e que, não raro, foi ouvido por uma única testemunha [...] Também o que é calado no curso da conversação banal, por medo, angústia ou pudor, soará no monólogo narrativo, no diálogo dramático. E aqui são os valores mais autênticos e mais sofridos que abrem caminho e conseguem aflorar à superfície do texto ficcional (BOSI, 2002, p. 135).

Para harmonizar essas duas instâncias no texto, Conceição Evaristo trabalha a emotividade e a poeticidade da linguagem, mostrando também o aspecto materno da resistência feminina negra, sobretudo no final do conto, quando se dá a multiplicação do pão sagrado e o milagre do leite materno.

O tom de discurso oral é dado desde o início do conto, pois a escrita de Conceição Evaristo é permeada pela oralidade advinda das muitas narrativas originárias da ancestralidade africana, trazidas, em especial, pelas mulheres de sua família:

Da mais velha de todas outras velhas, ouvi várias histórias e dentre tantas havia uma narração que me acompanhou a infância inteira. A do pão sagrado, alimento nascido 
das mãos de uma mãe para seus filhos, depois que ela, cozinheira, retornava da cozinha de sua patroa, Isabel Correa Pedragal.

A família Correa Pedragal, ainda hoje, é uma das famílias mais ricas da cidade de Imbiracitê, no estado de Campos Azuis. [...] E de geração a geração, os descendentes dos Correa Pedragal herdaram não só os bens materiais, mas também a prepotência de antigos senhores. Acostumados a mandos e desmandos, inclusive as mulheres, Dona Isabel Correa Pedragal e sua prole de sinhazinhas exerciam (ou exercem ainda) uma vigilância cruel sobre quem trabalha com eles. É desse contexto, fato ocorrido ainda no limiar dos anos 40, que a mais velha de todas as outras velhas de minha família, me contou uma história que eu não esquecerei jamais. (EVARISTO, 2016a, p. 37).

A voz narrativa do conto se insere na configuração benjaminiana, quando o autor se refere ao ato de narrar, delineando que: “A experiência que passa de pessoa a pessoa é a fonte a que recorreram todos os narradores. E, entre as narrativas escritas, as melhores são as que menos se distinguem das histórias orais contadas pelos inúmeros narradores anônimos." (BENJAMIN, 1986, p. 198).

Nesse sentido, podemos entender por que, mesmo entrando em contato com uma narrativa que pode acordar a revolta nos leitores e sua indignação diante dos fatos narrados ou que lhes pode suscitar lembranças difíceis de violências sofridas na vida real, na prática, depois da leitura, os leitores, no geral, se interessam em ler outros textos da escritora. Essa assertiva foi verdadeira em todas as situações em que trabalhamos os contos ou poemas de Conceição Evaristo na universidade ou em outros espaços de leitura.

\section{2 "O sagrado pão dos filhos" em círculo de leitura}

Um dos espaços de leitura para o qual levamos o conto "O sagrado pão dos filhos" foi o Memórias de Baobá, evento realizado desde 2010 por professores e alunos do Curso de Pedagogia da Universidade Federal do Ceará, tendo o centenário baobá, localizado na Praça do Passeio Público em Fortaleza-CE, como o principal espaço emblemático para a realização das atividades. O IX Memórias de Baobá, realizado no período de 21 a 24 de novembro de 2018, teve como tema "15 anos da lei 10.639/03: pertencimento, espiritualidade e educação", visando à promoção de diálogos formativos entre academia e comunidade em torno da transposição desses saberes e valores para a sala de aula.

Sob a sombra do baobá, junto a um público bastante diversificado, que incluía estudantes de Letras, Pedagogia, História, Ciências Sociais e professores da educação básica, ministramos o minicurso "A literatura afro-brasileira de autoria feminina e o letramento como prática de resistência," que propôs a experiência do letramento literário sob a perspectiva da resistência, com enfoque nas questões etnorraciais e de gênero a partir dos contos e poemas de Conceição Evaristo, tendo como base metodológica os círculos de leitura propostos por Rildo 
Cosson (2014). Pretendeu-se evidenciar a potencialidade da obra evaristeana no que concerne ao tema da resistência, à desconstrução de estereótipos sobre o universo feminino e sobre a afrobrasilidade, e contribuir para a formação de comunidades de leitores críticos, capazes de se perceberem como sujeitos da leitura, construtores de sentidos.

Acreditamos ser relevante para os alunos das diversas licenciaturas, que serão futuros professores e, portanto, formadores de leitores, incluir, nos seus repertórios de leitura, textos de Conceição Evaristo, notadamente por fazerem parte de uma literatura contra-hegemônica que, na maioria das vezes, não consta nos programas das disciplinas.

Conforme Cosson (2014), o círculo de leitura configura uma experiência privilegiada de leitura na qual seus integrantes se percebem como pertencentes a uma determinada comunidade leitora, apresentando três aspectos relevantes: Primeiro, "o caráter social da interpretação dos textos" e a apropriação e manipulação do repertório "com um grau maior de consciência"; segundo, "a leitura em grupo estreita os laços sociais, reforça identidades e a solidariedade entre as pessoas” e, terceiro, “os círculos de leitura possuem um caráter formativo." (COSSON, 2014, p. 139).

A execução do nosso círculo de leitura pautou-se no modelo "estruturado", obedecendo a uma formatação previamente estabelecida com papéis definidos para cada integrante e um roteiro para guiar as discussões, além da sugestão de registro das atividades. Assim, logo que apresentamos o tema e contextualizamos a escritora Conceição Evaristo na literatura afrobrasileira feminina, explicamos a sistematização das atividades do círculo de leitura a partir das fichas de função, as quais seriam assumidas/preenchidas pelos participantes do círculo. As funções pensadas por Daniels (2002) e sugeridas por Cosson para os círculos de leitura são as seguintes:

a) Conector- liga a obra ou o trecho com a vida, o momento;

b) Questionador- prepara perguntas sobre a obra para os colegas, normalmente de cunho analítico, tal como por que os personagens agem desse jeito? Qual o sentido deste ou daquele acontecimento?

c) Iluminador de passagens- escolhe uma passagem para explicitar ao grupo, seja porque é bonita, porque é difícil de ser entendida ou porque é essencial para a compreensão do texto;

d) Ilustrador- traz imagens para ilustrar o texto;

e) Dicionarista- escolhe palavras consideradas difíceis ou relevantes para a leitura do texto;

f) Sintetizador- sumariza o texto;

g) Pesquisador- busca informações contextuais que são relevantes para o texto;

h) Cenógrafo- descreve as cenas principais;

i) Perfilador- traça um perfil das personagens mais interessantes (COSSON, 2014, p. 143 ) 
Na prática do nosso minicurso, a metodologia dos círculos de leitura propiciou ao leitor a liberdade de escolha de uma ou mais funções, servindo como uma espécie de roteiro para a elaboração dos sentidos do texto. As funções mais escolhidas entre os participantes foram a de conector, perfilador, dicionarista e iluminador de passagens.

Em relação ao conto "O sagrado pão dos filhos", a função "conector" estabelecida pelos participantes se dirigiu, por um lado, para a história da escravidão no Brasil e, por outro, para a simbologia da maternidade. Houve um caloroso debate em torno do processo de exploração da população negra, abordando tanto seu passado de escravidão, quanto a situação atual de desvalorização do seu trabalho e da sua vida e corpo, sobretudo das mulheres. $\mathrm{O}$ aspecto da maternidade, bastante evidenciado no conto, possibilitou aos participantes uma identificação a ponto de cada um evocar a presença feminina em suas vidas, principalmente através de seus laços ancestrais com mães, tias, avós e bisavós. Nesse momento, toda a atenção se voltou para a escuta da história de vida daqueles que sentiram necessidade de compartilhar suas experiências.

Quando destacaram os perfis das personagens na função do perfilador, os leitores se apoiaram na temática do texto, que apresenta uma relação de dominação e subalternidade entre duas mulheres, patroa branca/empregada negra. Destacaram entre outras coisas que a opressão das mulheres negras extrapola a questão de gênero, sendo, portanto, interseccional, na medida em que envolve a raça e a classe. Além disso, salientaram a construção da humanidade das personagens negras evaristeanas, em especial no que se refere ao aspecto da maternidade, algo silenciado, no geral, na literatura brasileira canônica.

No que tange à função "iluminador de passagens", observamos a recorrência na menção, por parte dos leitores, do trecho relativo ao milagre da multiplicação dos farelos de pão no entresseio de Andina Magnólia, cena que eles associaram ao milagre bíblico da multiplicação dos pães.

Foi possível comprovar, na experiência com as fichas de função, que estas, muitas vezes, aparecem interligadas, o que, de certa forma, dinamiza o processo de construção dos sentidos do texto. A função "dicionarista", por exemplo, propiciou, no debate realizado sobre os nomes das personagens Andina Magnólia dos Santos e Isabel Correa Pedragal, não apenas a percepção em torno dos sentidos dos mesmos, mas o antagonismo de classes representado pelas personagens, corroborando, portanto, o traçado de seus perfis.

$\mathrm{Na}$ avaliação que fizemos ao término da oficina, os participantes em geral evidenciaram com entusiasmo o prazer e a fruição sentidos diante do texto de Conceição Evaristo e a importância de ser trabalhado na sala de aula, considerando a valorização da cultura afrodiaspórica como forma de superar o preconceito racial e fortalecer as ações de 
implementação da Lei $n^{\circ} 10.639 / 03$, que promove a valorização da história e da cultura afrobrasileiras nas escolas. Quanto à metodologia do círculo de leitura, os participantes ainda não a conheciam, mas consideraram-na bastante produtiva para a interação com o texto e com os integrantes do círculo.

\section{Considerações finais}

Considerando a obra de Conceição Evaristo como uma das mais representativas no cenário da literatura brasileira contemporânea, no que tange à categoria da resistência, procurou-se, na análise empreendida neste texto, destacar as singularidades com que é tecida a produção do humano, posto que este não existe como um pressuposto universalista abstrato, mas se realiza como prática discursiva. Nesse sentido, coube refletir sobre os processos que fazem do dizer ou calar um ato ético-estético. Tratando-se da obra literária, a resistência configura-se tanto na tessitura da narrativa, moldada por seus elementos internos (linguagem, espaço, tempo, personagens), quanto em sua conexão com outros espaços e tempos em que se pode recuperar "tematicamente cenas de um tempo histórico em que as vozes do discurso não serão só dos opressores, mas também dos silenciados e oprimidos que precisam falar". (PANTOJA, 2014, p. 21).

A resistência também está na linguagem e se realiza como resultado de uma consciência. Para Bakhitim/Volochínov (1996, p. 112), a consciência é feita de signo, morada do ideológico e os sujeitos dos discursos se tecem na confluência e no embate de diferentes vozes que disputam os sentidos do texto. Assim, o dizer nunca é neutro, mas sempre carregado de índices sociais de valor. Portanto, é na própria expressão escrita que se pode entrever a elaboração da produção discursiva das identidades, pela construção das personagens e pelo modo como são posicionadas umas frente às outras, numa dada situação comunicativa. A cena enunciativa, textualizada na literatura de resistência, ao tornar audível a multivocalidade, incluídas as vozes silenciadas pelo racismo, desnaturaliza a condição social do subalternizado, reconhecendo a representatividade de seu lugar de fala. A objetificação histórica do negro, reduzido ao status de força de trabalho pela lógica colonial, é subvertida e posta à prova pela emergência do ponto de vista do colonizado. O leitor é convocado a tomar posição na cena enunciativa, a desnaturalizar seu olhar, a ver o opressor sob a ótica do subalterno. Em outras palavras, a reconhecer a humanidade ocultada na produção discursiva colonizadora.

Em "O sagrado pão dos filhos", temos uma narrativa que recupera criticamente os modos de exploração que formataram a sociedade brasileira e ainda hoje se fazem presentes 
nas relações desiguais entre classe, gênero e etnia, saberes que foram mobilizados a partir da leitura e interpretação compartilhadas na nossa experiência do círculo de leitura, acordando a consciência dos leitores para a problemática em pauta.

\section{Referências}

BAKHTIN, Mikhail; Volochínov, V. N. Marxismo e filosofia da linguagem: problemas fundamentais do método sociológico na ciência da linguagem. Tradução de Michel Lahud e Yara Frateschi Vieira. 12. ed. São Paulo: Hucitec, 1996.

BARTHES, Roland. O prazer do texto. Tradução de J. Guinsburgl. São Paulo: 2008. (Elos, 2)

BENJAMIN, Walter. Obras escolhidas: magia e técnica, arte e política. 2. ed. São Paulo: Brasiliense, 1986.

BÍBLIA SAGRADA. Tradução de João Ferreira de Almeida. São Paulo: Sociedade Bíblica do Brasil, 2000.

BOSI, Alfredo. Literatura e resistência. São Paulo: Companhia das letras, 2002.

Narrativa e resistência. In: Revista Itinerários, Araraquara, n 10, 1996. p. 23.

Disponível em: <http://seer.fclar.unesp.br/itinerarios/article/viewFile/2577/2207>. Acesso em: 13 jun. 2017.

COSSON, Rildo. Círculos de leitura e letramento literário. São Paulo: Contexto, 2014.

DICIONÁRIO Priberam da Língua Portuguesa [em linha], 2008-2013. Disponível em: <https://www.priberam.pt/dlpo/magn\%C3\%B3lia>. Acesso em: 24 jun. 2018.

DUARTE, Eduardo de Assis; LOPES, Elisângela. Conceição Evaristo: literatura e identidade. In: Literafro: o portal da literatura afrobrasileira. UFMG, 2018. Disponível em: $<$ http://www.letras.ufmg.br/literafro/autoras/29-critica-de-autores-feminios/199-conceicaoevaristo-literatura-e-identidade-critica $>$. Acesso em: 22 out.2018.

EVARISTO, Conceição. Histórias de leves enganos e parecenças. Rio de Janeiro: Malê, 2016.

O entrecruzar das margens - gênero e etnia: apontamentos sobre a mulher negra na sociedade brasileira. In: DUKE, Dawn. (Org.). A escritora afro-brasileira: ativismo e arte literária. Belo Horizonte: Nandyala, 2016, p. 100/110.

Literatura negra: uma poética da nossa afro-brasilidade. Scripta. Belo Horizonte, v. 13, n. 25, 2009, p. 17-31.

LIMA, Juliana Domingos de. Conceição Evaristo: Minha escrita é contaminada pela condição de mulher negra (Entrevista). Jornal Nexo, 2017. Disponível em:

<https://www.nexojornal.com.br/entrevista/2017/05/26/>. Acesso em: 10 out. 2018. 
MAINGUENEAU, Dominique. Cenas da enunciação. POSSENTI, Sírio; SOUSA E SILVA, Maria Cecília Perez de. (Orgs.) São Paulo: Parábola Editorial, 2008.

Recebido em: 10/02/2019 Aceito para publicação em: 20/03/2019 